\title{
Rekreatif Amaçlı Spor Yapan Bireylerin İzokinetik Diz Kuvvetlerinin Değerlendirilmesi
}

\author{
Ali Kerim YILMAZ ${ }^{1 *}$ \\ ${ }^{1}$ Ondokuz Mayıs Üniversitesi Yaşar Doğu Spor Bilimleri Fakültesi, SAMSUN
}

DOI: 10.31680/gaunjss.713473

Orijinal Makale / Original Article

Geliş Tarihi / Received: 02.04.2020

Kabul Tarihi / Accepted:07.05.2020

Yayın Tarihi / Published: 15.06.2020

\section{Öz}

Mevcut araştırmanın amacı, rekreatif amaçlı spor yapan bireylerin izokinetik diz kuvvetlerinin değerlendirilmesidir. Çalışmaya rekreatif amaçıı spor yapan 10 erkek sağlıklı birey dahil edilmiştir. Deneklerin boy, kilo ve vücut kütle indeksi (VKi) parametrelerini belirlemek için Gaia 359 Plus BodyPass analizörü, izokinetik diz kuvvetlerin belirlenmesi için ise Humac Norm Cybex izokinetik dinamometre kullanılmıştır. İstatistiksel analiz için SPSS 21. paket programı kullanıldı. Dominant(D) ve non dominant (ND) tarafların karşılaştırılmasında paired sample t-testi uygulandı. $60^{\circ} \mathrm{sn}^{-1}$ açısal hızda hem Ekstansiyon (Eks) hem defleksiyon (Fleks) kuvvetlerinde $\mathrm{D}$ taraf lehine anlamlılık tespit edilirken $(p<0,05), 180^{\circ} \mathrm{sn}^{-1}$ ve $240^{\circ} \mathrm{sn}^{-1}$ açısal hızlarda herhangi bir anlamlılık yoktu $(p>0,05) .60^{\circ}$ $\mathrm{sn}^{-1}, 180^{\circ} \mathrm{sn}^{-1}$ ve $240^{\circ} \mathrm{sn}^{-1}$ açısal hızlarda hamstring/quadriceps (H/Q) oranlarında anlamlılığa rastlanmadı $(p>0,05)$. Yorgunluk indekslerinin (Yi)Eks fazında anlamlılık vardı $(p<0,05)$. Sonuç olarak rekreatif amaçlı spor yapan bireylerde düşük açısal hızlarda D ve ND tarafta kuvvet farklılıkları ortaya çıkarken, yüksek açısal hızlarda kuvvet değerlerinin benzer olduğu saptandı. Ayrıca D ve ND taraflarda tüm açısal hızlarda H/Q oranlarının ve $Y \dot{I}$ değerlerinin benzer sonuçlar ortaya koyduğu, H/Q oranlarının açısal hızlara göre sakatıı riski aralıklarında olmadığı tespit edildi.

Anahtar Kelimeler: İzokinetik diz kuvveti, H/Q oranı, Yorgunluk indeksi

\section{Evaluation of Isokinetic Knee Strength of Individuals Doing Sports for Recreational Purposes}

\begin{abstract}
The aim of the present study is to evaluate the isokinetic knee strength of individuals who do sports for recreational purposes. 10 male healthy individuals engaged in recreational sports were included in the study. Gaia 359 Plus Body Pass analyzer was used to determine the height, weightand body mass index (BMI) parameters of the subjects, and Humac Norm Cybex isokinetic dynamometer for determining isokinetic knee stregth. SPSS 21. package program was used for statistical analysis. Paired sample t-test was used to compare dominant (D) and nondominant (ND) sides. $60^{\circ} \mathrm{sn}^{-1}$ angular velocity, both extansion (Eks) and flexion (Fleks) strength were found significant in favor of $D$ side $(p<0.05)$, there was no significance at $180^{\circ} \mathrm{sn}^{-1}$ and $240^{\circ} \mathrm{sn}^{-}$ ${ }^{1}$ angular velocities ( $p>0.05$ ). No significance was found in hamstring/quadriceps (H/Q) ratiosat $60^{\circ} \mathrm{sn}^{-1}, 180^{\circ} \mathrm{sn}^{-}$ ${ }^{1}$ and $240^{\circ} \mathrm{sn}^{-1}$ angular speeds ( $\left.p>0.05\right)$. Signifance was found in fatigue index's Eksphase $(p<0.05)$. As a result, it was determined that in individuals who do sports for recreational purposes, strength differences were observed on the D and ND sides at low angular speeds, where as strength values were similar at high angular speeds. In addition, it was determined that $\mathrm{H} / \mathrm{Q}$ ratios and $\mathrm{FI}$ values at all angular velocities on $\mathrm{D}$ and ND sides showed similar results, and H/Q ratios were not in disability risk ranges compared to angular velocities.
\end{abstract}

Keywords: Isokinetic knee strength, H/Q ratio, fatigue index

\footnotetext{
* Sorumlu Yazar: Ali Kerim YILMAZ
}

E-mail: alkrm_ylmz@hotmail.com 


\section{Giriş}

Kas gruplarının ortaya çıkardığı maksimum kuvvet ve aynı ekleme farklı hareketleri yaptırmayı sağlayan kas gruplarının kuvvetleri günümüzde izokinetik dinamometreler sayesinde objektif bir şekilde ölçülebilmektedir (Agre ve Baxter, 1987; Malliou ve ark., 2003). Ortaya çıkan kuvvetin değerlendirilmesi kas grupları arasından objektif bir değerlendirme sağlarken potansiyel sakatlık riski oluşumlarını da tahmin etmeye yardımcı olur (Lehnert ve ark., 2014; Maly ve ark., 2015).Fiziksel aktivite düzeyi az yada çok tüm bireylerde kas kuvvetleri arasındaki güç dengesizlikleri sakatlıklara olan yatkınlığı belirlemede kullanılan ve geçerliliği en yüksek olan tahmin edicilerdir (Maly ve ark., 2015).

Spor branşlarında ve fiziksel aktivite esnasında büyük öneme sahip olan diz eklemi kasları quadriceps $(\mathrm{Q})$ ve hamstring $(\mathrm{H})$ araştırmacıları bu kas grubuna yönelik uygulanan farklı antrenman metotları, akut veya kronik yüklemelerle ortaya çıkardıkları kuvvet ve sakatlıklara yatkınlıklarını belirlemek adına agonist ve antagonist taraflardaki lateral kuvvet oranlarıla ilgili çalışmalar yapmalarına neden olmuştur (Andrade ve ark., 2012; Drid ve ark., 2010; Thomas ve ark., 2009;Zakas ve ark., 1995). Alt ekstremite için asimetrik güç hem sağ hem de sol taraftaki quadriceps ve hamstring kaslarının benzer kasılma türlerinde eşit miktarda kuvvet üretememesi olarak tanımlanabilir (Keeley ve ark., 2011). Araştırmacılar farklı branşlar ve sporcu grupları üzerinde farklı antrenman metotları, ısınma türleri ve ek uygulamaların izokinetik diz kuvveti ve sakatlıklara yatkınlıkları belirlemek adına akut ver kronik etkilerini incelemiş olsalar da (Chen ve ark., 2007; Doğan ve ark., 2019; Yeefun ve ark., 2002) kapsamı ve içeriği az olan rekratif amaçlı spor yapan bireylerde ki araştırmaların kısıtlı sayıda olduğu görülmektedir.

Tüm bu bilgilerden yola çıkarak mevcut araştırmanın amacı,rekreatif amaçlı spor yapan bireylerin dominant (D) ve nondominant (ND) taraflarda ortaya çıkardıkları izokinetik diz kuvvetlerinin ekstansiyon (Eks) ve fleksiyon fazlarında (Fleks) pik tork (PT) değerlerini ayrıca bu değerlerden ortaya çıkan $H / Q$ oranları ve yorgunluk indekslerinin (Yi) değerlendirilmesidir. Araştırma rekreatif amaçlı spor yapan bireylerin D ve ND taraflarda izokinetik diz kuvvetlerinin benzer olacağı üzerine hipotezlenmiştir. 


\section{Yöntem}

Mevcut araştırma rekreatif amaçlı spor yapan bireylerin diz izokinetik eks ve fleks kuvvetlerinin belirlenmesi ile $\mathrm{Q}$ ve $\mathrm{H}$ kaslarındaki asimetrik güç farklılıklarının incelenmesini kapsamaktadır. Bu kapsamda denekler iki defa laboratuar ortamında, teste tabi tutulmuşlardır. İlk laboratuar ziyaretinde deneklere uygulanacak test protokolleri hakkında bilgi verilmiş ardından boy, kilo ve vücut kütle indeksleri (VKİ) ölçümleri alınmıştır. İkincide ise deneklere izokinetik diz kuvvetleri ölçümleri $60^{\circ} \mathrm{sn}^{-1}$, $180^{\circ} \mathrm{sn}^{-1}$ ve $240^{\circ} \mathrm{sn}^{-1}$ açısal hızlarda konsantrik zirve tork değerleri belirlenmesi için yapılmıştır. Deneklerden testi maksimum eforla yapmaları istenmiştir. Ölçümlerden 24 saat öncesine kadar deneklere herhangi bir egzersiz ya da fiziksel aktivite yapmamaları hususunda uyarılmışlardır.

\section{Katılımcılar}

Çalışmaya rekreatif amaçlı spor yapan 10 erkek sağlıklı birey (yaş 25,80 yıl, boy 176,2 cm, kilo 69,20 kg, Vki 19,62 kg/m² ) dahil edilmiştir (Tablo 1). Deneklerin daha önceden diz bölgesi sakatlıkları geçirmemiş olmasına dikkat edilmiştir.

\section{Tanımlayıcı bilgilerin belirlenmesi}

Çalışmaya katılan deneklerin boy, kilo ve VKI parametrelerini belirlemek için Gaia 359 Plus BodyPass analizörü kullanılmıştır. denekler analizör üzerine çıplak ayakla, tişört ve şort giyilmiş şekilde çıkarılmış sonuçlar boy $(\mathrm{cm})$, kilo $(\mathrm{kg})$, VKİ değerleri olarak kaydedilmiştir.

\section{Diz İzokinetik Kuvvet Ölçümleri}

Deneklerin diz eks ve fleks hareketinde sergilemesi istenen PT açısal hızları $60^{\circ} \mathrm{sn}^{-1}, 180^{\circ} \mathrm{sn}^{-1}$ ve $240^{\circ} \mathrm{sn}^{-1}$ olarak belirlenmiştir. Testler bilgisayar kontrollü izokinetik dinamometre (Humac Norm Testing and Rehabilitation System, CSMI, USA) ile yapılmıştır. Testler tüm deneklere gündüz 11:00 ve 13:00 saatleri arasında yaptırılmıştır. Deneklere testler uygulanmadan önce genel ısınma için, $5 \mathrm{dk}$ süre ile düşük yoğunluklu aerobik nitelikli koşu ile alt ekstremite kaslarına yönelik önce dinamik ve ardından statik olmak üzere 10 dakika germe uygulamaları yapıldı. Açısal hızlarda $60^{\circ} \mathrm{sn}^{-1}$ için 3 deneme ve 30 saniyelik dinlenmeden sonra 5 maksimal tekrar, $180^{\circ} \mathrm{sn}^{-1}$ için 3 deneme ve 30 saniyelik dinlenmeden sonra 5 maksimal tekrar, $240^{\circ} \mathrm{sn}^{-1}$ için ise 3 deneme ve 30 saniyelik dinlenmenin ardından 15 maksimal tekrar yapılacağı uyarısı yapıımıştır. $240^{\circ} \mathrm{sn}^{-1}$ açısal hızda 15 maksimal tekrar deneklerin 
Yılmaz AK., (2020). Rekreatif Amaçlı Spor Yapan Bireylerin İzokinetik Diz Kuvvetlerinin Değerlendirilmesi. Gaziantep Üniversitesi Spor Bilimleri Dergisi, 5(2), 146-153.

Yl'lerini belirlemek amacıyla yapılmışı̧ı. Deneme tekrarları deneklerin adaptasyonları sağlamak ve sakatııtan korunmak adına yaptırımıştır. Tüm test süresince her denek temel itiş/çekiş ve kalan tekrar sayıları hakkında sözlü olarak cesaretlendirilmiş ve deneklerin PT değerlerinin en üst seviyede çıkabilmesi adına sürekli olarak yüksek seste cesaretlendirici sözler söylenmiştir. Teste başlamadan önce tüm deneklere test esnasında testin olumlu geçmesi ve maksimal sonuçları alabilmemiz için diz kuvvetlerini maksimal düzeyde kullanmaları istenmiştir. Tüm açısal hızlarda çıkan PT değerleri Newton (Nm) olarak kaydedilmiştir.

\section{İstatistiksel Analiz}

İstatistiksel analiz için SPSS paket programı (SPSS for Windows, sürüm 21.0, SPSS Inc., Chicago, Illinois, ABD) kullanıldı. Veriler; aritmetik ortalama, standart sapma olarak sunuldu. Normallik sınaması için Shapiro-Wilk testi; homojenlik sınaması için Levene testi uygulandı. Normal dağılım göstermeyen veri setleri için çarpıklık ve basıklık değerleri kontrol edildi ve \pm 2 değeri içinde olan veri setlerinin normal dağılım gösterdiği kabul edildi. D ve ND tarafların karşılaştıııımasında paired sample t-testi uygulandı.

\section{Bulgular}

Tablo 1. Deneklerin tanımlayıcı verileri

\begin{tabular}{|c|c|c|c|c|}
\hline & Min. & Maks. & Ort. & S.S \\
\hline Yaş (yıl) & 24,00 & 29,00 & 25,80 & 2,09 \\
\hline Boy $(\mathrm{cm})$ & 168 & 190 & 176,2 & ,069 \\
\hline Kilo (kg) & 57,00 & 87,00 & 69,20 & 9,77 \\
\hline Vki $\left(\mathrm{kg} / \mathrm{m}^{2}\right)$ & 16,01 & 24,03 & 19,62 & 2,49 \\
\hline
\end{tabular}

Deneklerin fiziksel parametreleri yaş 25,80 yıl, boy $176,2 \mathrm{~cm}$, kilo $69,20 \mathrm{~kg}$, vki $19,62 \mathrm{~kg} / \mathrm{m}^{2}$ olarak tespit edildi (Tablo 1).

Tablo 2. Deneklerin D ve ND taraflarda ki izokinetik Eks ve Fleks Değerlerinin Karşılaştırıması

\begin{tabular}{|c|c|c|c|c|c|}
\hline & & Ort. & S.S & $t$ & $\mathbf{p}$ \\
\hline $60^{\circ} \mathrm{Eks}(\mathrm{Nm})$ & $\begin{array}{c}\mathrm{D} \\
\mathrm{ND}\end{array}$ & $\begin{array}{l}166,80 \\
147,90\end{array}$ & $\begin{array}{l}33,73 \\
22,51\end{array}$ & 3,187 & $0,011^{*}$ \\
\hline $180^{\circ} \mathrm{Eks}(\mathrm{Nm})$ & $\begin{array}{c}\mathrm{D} \\
\mathrm{ND}\end{array}$ & $\begin{array}{c}102,90 \\
94,00\end{array}$ & $\begin{array}{l}16,98 \\
14,79\end{array}$ & 3,503 & $0,007^{*}$ \\
\hline $240^{\circ} \mathrm{Eks}(\mathrm{Nm})$ & $\begin{array}{c}\mathrm{D} \\
\mathrm{ND}\end{array}$ & $\begin{array}{l}84,20 \\
78,60\end{array}$ & $\begin{array}{l}13,02 \\
11,98\end{array}$ & 2,037 & 0,072 \\
\hline $60^{\circ}$ Fleks (Nm) & $\begin{array}{c}\mathrm{D} \\
\mathrm{ND}\end{array}$ & $\begin{array}{c}100,60 \\
99,80\end{array}$ & $\begin{array}{l}25,67 \\
17,63\end{array}$ & 0,116 & 0,910 \\
\hline $180^{\circ}$ Fleks (Nm) & $\begin{array}{c}\mathrm{D} \\
\mathrm{ND}\end{array}$ & $\begin{array}{l}70,50 \\
65,40\end{array}$ & $\begin{array}{l}18,11 \\
11,89\end{array}$ & 1,098 & 0,301 \\
\hline $240^{\circ}$ Fleks ( $\left.\mathrm{Nm}\right)$ & $\begin{array}{c}\mathrm{D} \\
\mathrm{ND}\end{array}$ & $\begin{array}{l}62,30 \\
60,00\end{array}$ & $\begin{array}{c}11,77 \\
9,32\end{array}$ & 0,753 & 0,471 \\
\hline
\end{tabular}

${ }^{\star} \mathrm{p}<0,05$ 
Tablo 2.'de deneklerin $\mathrm{D}$ ve ND taraflardaki izokinetik diz eks ve fleks kuvvetleri $60^{\circ} \mathrm{sn}^{-1}, 180^{\circ} \mathrm{sn}^{-1}$ ve $240^{\circ} \mathrm{sn}^{-1}$ açısal hızlarda değerlendirilmiştir. Bu sonuçlara göre $60^{\circ} \mathrm{sn}^{-1}$ açısal hızda hem Eks hemde Fleks kuvvetlerinde $D$ taraf lehine anlamlılık tespit edilirken $(p<0,05), 180^{\circ} \mathrm{sn}^{-1}$ ve $240^{\circ} \mathrm{sn}^{-1}$ açısal hızlarda $D$ ve ND taraf arasında herhangi bir anlamlılı̆a rastlanmamıştır $(p>0,05)$.

Tablo 3. Deneklerin $D$ ve ND taraflarda $\mathrm{ki} H / \mathrm{Q}$ oranları ve $\mathrm{Yi}$ değerlerinin karşılaştırııması

\begin{tabular}{|c|c|c|c|c|c|}
\hline & & Ort. & S.S & $\mathbf{t}$ & $\mathbf{p}$ \\
\hline $60^{\circ} \mathrm{H} / \mathrm{Q}(\%)$ & $\begin{array}{c}\mathrm{D} \\
\mathrm{ND}\end{array}$ & $\begin{array}{l}61,00 \\
68,10 \\
\end{array}$ & $\begin{array}{l}10,26 \\
11,29 \\
\end{array}$ & $-1,872$ & 0,094 \\
\hline $180^{\circ} \mathrm{H} / \mathrm{Q}(\%)$ & $\begin{array}{c}\text { D } \\
\text { ND }\end{array}$ & $\begin{array}{l}68,70 \\
71,40 \\
\end{array}$ & $\begin{array}{c}10,89 \\
9,77 \\
\end{array}$ &,- 648 & 0,533 \\
\hline $240^{\circ} \mathrm{H} / \mathrm{Q}(\%)$ & $\begin{array}{c}\mathrm{D} \\
\mathrm{ND}\end{array}$ & $\begin{array}{l}74,80 \\
77,50 \\
\end{array}$ & $\begin{array}{l}9,55 \\
8,80 \\
\end{array}$ &,- 676 & 0,516 \\
\hline Yi(Eks) & $\begin{array}{c}\text { D } \\
\text { ND }\end{array}$ & $\begin{array}{l}36,10 \\
31,90\end{array}$ & $\begin{array}{l}5,74 \\
7,53\end{array}$ & 2,957 & $0,016^{*}$ \\
\hline Yí(Fleks) & $\begin{array}{c}\mathrm{D} \\
\mathrm{ND}\end{array}$ & $\begin{array}{l}30,40 \\
30,20\end{array}$ & $\begin{array}{l}9,72 \\
9,28\end{array}$ & 0,213 & 0,836 \\
\hline
\end{tabular}

${ }^{\star} \mathrm{p}<0,05$

Tablo 3.'de deneklerin $D$ ve ND taraflarda ki $H / Q$ oranları ve $Y I ̇$ değerlerinin karşılaştııımıştır. Ortaya çıkan sonuçlara göre $60^{\circ} \mathrm{sn}^{-1}, 180^{\circ} \mathrm{sn}^{-1}$ ve $240^{\circ} \mathrm{sn}^{-1}$ açısal hızlarda $H / Q$ oranlarında herhangi bir anlamlıı̆ga rastlanmadı $(p>0,05)$. Ancak240 $\mathrm{sn}^{-1}$ derece açısal hızdan hesaplanan $\mathrm{YI}(\mathrm{Eks})$ değerinde istatistiksel olarak anlamlılık vardır $(p<0,05)$.

\section{Tartışma ve Sonuç}

$\mathrm{Bu}$ araştırma rekreatif amaçlı spor yapan bireylerin izokinetik diz kuvvetlerinin belirlenmesi, bu kişilerde $H$ ve $Q$ kaslarının kuvvet üretiminde birbirlerine olan oranlarının tespit edilmesi aynı zamanda da her iki kas grubunda ortaya çıkan Yi değerlerini tespit etmek amacıyla yapıldı. Araştırma sonucunda üç anlamlı bulgu tespit edildi. Bunlar; $60^{\circ} \mathrm{sn}^{-1}$ açısal hızın eks ve fleks fazlarında $D$ tarafın ND tarafa göre daha güçlü olmasıydı. Sonuncusu ise $Y \grave{l}$ indekslerinin eks fazında $D$ tarafında ND tarafa oranla daha yüksek Yì değerleri ortaya çıkarmasıydı. Sağlıklı bireyler üzerinde yapılan diz izokinetik kuvvet çalışmaları incelendiğinde, Doğan ve ark. (2019), yaptıkları araştırmada sağlıklı bireyler üzerinde yaptıkları araştırmada Kinezyo bant (KB) uygulamasının izokinetik diz kuvvetine olan etkilerini incelemiş ve KB uygulanmadan yapılan ilk ölçümlerde mevcut araştırma ile benzer sonuçlar ortaya çıkarmıştır. Kaçoğlu (2019), sağlıklı bireyler üzerinde diz izokinetik kuvvetinde cinsiyet arası asimetrik farklııkları incelemiş fiziksel olarak aktif ancak üst düzeyde antrenmanlı olmayan bireylerde düşük, orta ve yüksek açısal hızlardaki kontra lateral 
Yılmaz AK., (2020). Rekreatif Amaçlı Spor Yapan Bireylerin İzokinetik Diz Kuvvetlerinin Değerlendirilmesi. Gaziantep Üniversitesi Spor Bilimleri Dergisi, 5(2), 146-153.

izokinetik diz kuvvetleri simetri açı değerlerinin kadın ve erkeklerde benzer olduğunu bildirmiştir. Ön ve ark.(2020), beden eğitimi ve spor yüksekokulu dışında farklı fakültelerde okuyan öğrencilere 8 haftalık step aerobik egzersizlerinin izokinetik diz kuvvetine olan etkisini incelemiş ve egzersizlere başlamadan önce yapılan testler araştırmamızla benzer sonuçlar ortaya çıkarmışlardır. Miçooğulları ve ark. (2016), amatör düzeyde sporla ilgilenen bireylerin fiziksel aktivite düzeylerine göre izokinetik diz kuvvetlerini değerlendirmiş ve hem düşük hem de yeterli fiziksel aktivite düzeyine sahip bireylerde bir farklıık saptamamışlardır, ayrıca bu araştırma bulguları da mevcut araştırmamız sonuçları ile örtüşmektedir. Elit düzeyde spor yapan bireyler üzerinde yapılan araştırmalar incelendiğinde, üst düzeyde liglerde oynayan sporcuların sonuçları hem izokinetik kuvvet hem de $H / Q$ oranları ve $Y i$ bakımından mevcut araştırmamız sonuçlarından daha iyi sonuçlar ortaya koymaktadır (Aginsky ve ark., 2014; Cometti ve ark., 2001; Newman ve ark., 2004; Masuda ve ark., 2005; Rahnama ve ark., 2005; Yılmaz ve ark., 2019). Ancak elit sporcularda da amatör ve 3.lig düzeyinde spor yapan sporcular ile mevcut araştırmamız sonuçlarının benzerlik gösterdiği ancak genç milli takımlar ve profesyonel sporculara göre düşük sonuçlar ortaya çıkardığı görülmektedir (Gür ve ark.,1999; Young ve ark., 1996). Ayrıca yapılan çalışmadaki gibi diğer çalışmalarda da açısal hız artııça kuvvet oranının düştüğü tespit edilmiştir.

Sonuç olarak, mevcut araştırmamızda rekreatif amaçlı spor yapan bireylerde ortaya çıkan izokinetik kas kuvvetlerinin fiziksel aktivite düzeyi normal olan, amatör düzeyde spor yapan bireyler ile benzer sonuçlar ortaya çıkardığı. Araştırmamızdaki deneklerin H/Q kuvvetlerinde asimetrik sonuçların olmadığı, ortaya çıkan kuvvet Yi değerlerinde özellikle $D$ tarafta ortaya çıkan yorgunluğun kasın kuvvet üretimi bakımından yeterli ancak özellikle eks fazında $Q$ kasının yeterli düzeyde dayanıkııı̆a sahip olmadığından kaynaklandığı söylenebilir. İleride yapılacak araştırmaların fiziksel aktivite düzeyi düşük ve orta bireylere uygulanacak farklı egzersiz ve kas kuvvetini artırmaya yönelik kullanılan farklı uygulamalar ile diz izokinetik kuvvetine olan akut ve kronik etkilerinin incelenmesi literatüre katkı sağlayacaktır. 


\section{Kaynaklar}

Aginsky JD, Neophytou N, Charalambous T. (2014). Isokinetic hamstring and quadriceps muscle strength profiles of elite South African football players. African Journal for Physical, Health Education, Recreation and Dance. 20(3-2), 1225-1236.

Agre JC, Baxter TL. (1987). Musculo skeletal profile of male collegiate soccer players. Arch Phys Med Rehabil. 68(3), 147-150.

Andrade M, De Lira C, Koffes F, Mascarin N, Benedito-Silva A, Da Silva A. (2012). Isokinetic hamstrings-to-quadriceps peak torque ratio: the influence of sport modality, gender, and angular velocity. J Sports Sci. 30, 547-553.

Boguszewska K, Boguszewski D, Busko K. (2010). Special Judo Fitness Test and biomechanics measurements as a way to control of physical fitness in young judoists. Arch Budo. 6, 205-209

Chen WC, Hong WH, Huang TF, Hsu HC. (2007). Effects of kinesio taping on the timingand ratio of vastus medialis obliquus and vastus lateralis muscle for person with patello femoral pain. J Biomech. 40, 318.

Cometti G, Maffiuletti NA, Pousson M, Chatard JC, Maffulli N. (2001). Isokinetic strength and an aerobic power of elite, sub elite and amateur French soccer players. International journal of sports medicine. 22(01), 45-51.

Doğan E, Yilmaz AK, Özdal M, Mayda MH, Yilmaz Ç, Ermiş E. (2019). Acute effects of reverse Kinesio Taping on knee muscle strength, fatigue index and H/Q ratio in healthy subjects. Isokinetics and Exercise Science. 27(2),135-141.

Drid P, Drapsin M, Trivic T, Bratic M, Obadov S. (2010). Thigh muscles flexion/ extension ratio in elite judo players. J Combat Sports and Martial Arts. 1(1), 21-25.

Kaçoğlu C. (2019). Diz Eklem Kuvveti Asimetrisinde Cinsiyetler Arası Farklılıkların İncelenmesi. Spor Hekimliği Dergisi. 54(4), 225-232.

Keeley DW, Plummer HA, Oliver GD. (2011). Predict in gasym metrical lower extremity strength deficits in college-aged men and women using common horizontal and vertical power field tests: a possible screening mechanism. J Strength Cond Res. 25, 1632-1637

Lehnert M, Xaverova Z, De SteCroix M. (2014). Changes in Muscle Strength in U19 Soccer Players During an Annual Training Cycle. J Hum Kinet. 42, 175-185 
Malliou P, Ispirlidis I, Beneka A, Taxildaris K, Godolias G. 2003). Vertical jump and knee extensors isokinetic performance in Professional soccer players related to the phase of the training period. Isokinet Exerc Sci. 11(3), 165-169.

Masuda K, Kikuhara N, Demura, S, Katsuta S, Yamanaka K. (2005). Relation ship between muscle strength in various isokinetic movementsandkick performance among soccer players. Journal of Sports Medicine and Physical Fitness. 45(1), 44.

Miçooğulları A, Yıldızgören MT, Turhanoğlu AD, Üstün N, Güler H. (2016). Amatör sporcularda fiziksel aktivite düzeyleri ile izokinetik kas performansı. Turk J Osteoporos. 9, 22-35.

Newman MA, Tarpenning KM, Marino FE. (2004). Relation ships between isokinetic knee strength, single-sprint performance, and repeated-sprint ability in football players. TheJournal of Strength \& Conditioning Research. 18(4), 867-872.

Ön BO, Yıldız M, Dündar Ü. (2020). 8 Haftalık Step Aerobik Egzersizlerin Diz Eklemi İokinetik Kuvvet, Denge Ve Yaşam Kalitesi Üzerine Etkisi. Kocatepe Tıp Dergisi. 21(1), 82-91.

Rahnama N, Lees A, Bambaecichi E. (2005). A comparison of muscle strength and flexibility between the preferred and non-preferred leg in English soccer players. Ergonomics. 48(11-14), 1568-1575.

Thomas K, French D, Hayes PR. (2009). Theeffect of two plyometric training techniques on muscular power and agility in youth soccer players. J Strength Cond Res. 23(1), 332-335.

Yeefun S, Hirunrat S, Chentanz T. (2002). Hamstring to quadriceps strength ratio in Mahidol University soccerp layers. J Health Sci. 11, 201-209.

Yılmaz AK, Kabadayı M, Bostancı Ö, Özdal M, Mayda MH. (2019). Analysis of isokinetic knee strength in soccer players in terms of selected parameters. Physical education of students. 23(4), 209-216. 